\title{
Review \\ Clinical review: Prognostic value of magnetic resonance imaging in acute brain injury and coma
}

\author{
Nicolas Weiss ${ }^{1}$, Damien Galanaud ${ }^{2}$, Alexandre Carpentier ${ }^{3}$, Lionel Naccache ${ }^{4}$ \\ and Louis Puybasset ${ }^{1}$
}

\begin{abstract}
1'Department of Anesthesiology and Critical Care, Pitié-Salpêtrière Teaching Hospital, Assistance Publique - Hopitaux de Paris and Pierre et Marie Curie University, Bd de l'hôpital, 75013, Paris, France

${ }^{2}$ Department of Neuroradiology, Pitié-Salpêtrière Teaching Hospital, Assistance Publique - Hopitaux de Paris and Pierre et Marie Curie University, Bd de l'hôpital, 75013, Paris, France

${ }^{3}$ Department of Neurosurgery, Pitié-Salpêtrière Teaching Hospital, Assistance Publique - Hopitaux de Paris and Pierre et Marie Curie University, Bd de l'hôpital, 75013, Paris, France

${ }^{4}$ Department of Neurophysiology, Pitié-Salpêtrière Teaching Hospital, Assistance Publique - Hopitaux de Paris and Pierre et Marie Curie University, Bd de l'hôpital, 75013, Paris, France
\end{abstract}

Corresponding author: Louis Puybasset, louis.puybasset@psl.aphp.fr

Published: 18 October 2007

This article is online at http://ccforum.com/content/11/5/230

(c) 2007 BioMed Central Ltd
Critical Care 2007, 11:230 (doi:10.1186/cc6107)

their medical cost has been estimated at US\$1 to 7 billion per year in the USA [5]. The possibility that aggressive medical management may lead to survival with severe brain impairment raises ethical issues. Adapting the level of medical care to long-term neurological prognosis is a major challenge for neurological intensive care. The first step in meeting this challenge is validation of tools that accurately predict longterm neurological outcome after severe cerebral insult.

Magnetic resonance imaging (MRI) is more sensitive than computed tomography at detecting stroke in the early phase, subtle abnormalities related to anoxic/hypoxic encephalopathy, and diffuse axonal injury (DAI) in patients with TBI. MRI provides valuable diagnostic information, although it is cumbersome to perform in the acute phase in comatose patients who are undergoing mechanical ventilation. Several MRI sequences and techniques have been used to explore the structures, metabolism and functions of the brain. The data supplied by these methods could be used to predict long-term neurological outcome.

In this review we briefly describe the MRI sequences and techniques used in critically ill neurological patients, and then we discuss their prognostic value in comatose patients with $\mathrm{TBI}$, anoxic/hypoxic encephalopathy, or stroke. Finally, we discuss the prognostic influences of the main anatomical structures that are involved in arousal and awareness, and we suggest avenues for future research.

$A D C=$ apparent diffusion coefficient; ARAS = ascending reticular activating system; DAI = diffuse axonal injury; DTI = diffusion tensor imaging; $\mathrm{DWI}=$ diffusion weighted imaging; FLAIR = fluid-attenuated inversion recovery; GOS = Glasgow Outcome Scale; MRI = magnetic resonance imaging; $\mathrm{MRS}=$ magnetic resonance spectroscopy; $\mathrm{NAA}=N$-acetyl-aspartate; $\mathrm{TBI}=$ traumatic brain injury. 


\section{Magnetic resonance imaging sequences and techniques \\ Conventional magnetic resonance imaging}

Conventional MRI relies chiefly on four sequences [6]. Fluidattenuated inversion recovery (FLAIR) is the primary sequence used in neuroradiology (Figure 1). It detects brain contusion, brain oedema and subarachnoid or intraventricular haemorrhage, as well as the resulting ventricular dilatation or herniation. The $T 2^{*}$-weighted sequence is more sensitive to intraparenchymal blood than is FLAIR. This sequence can also reveal haemorrhagic DAI [7,8]. The T2-weighted sequence completes the FLAIR sequence and provides greater detail on brainstem and central grey matter. Finally, diffusion weighted imaging (DWI) is sensitive to random movement of water molecules. This sequence shows cerebral oedema and distinguishes cytotoxic from vasogenic oedema. It is used chiefly in patients with ischaemic stroke.

Conventional MRI provides an initial evaluation of brain lesions. However, when it is used alone it fails to predict outcome accurately.

\section{Magnetic resonance spectroscopy}

This sequence is a noninvasive technique for assessing brain metabolism in vivo. Proton-magnetic resonance spectroscopy (MRS) is most commonly used. Four main markers are studied: the peak of $\mathrm{N}$-acetyl-aspartate (NAA), an amino acid present in neurones, which reflects the status of neuronal tissue; creatine, found in glia and neurones, which serves as a point of reference because its level is believed to be stable; choline, a constitutive component of cell membranes, which reflects glial proliferation or membrane breakdown [9]; and lactate, a marker of anaerobic metabolism and therefore of ischaemia [10]. As shown in Figure 2, three main pons monovoxel profiles may be observed in patients with TBI.

\section{Diffusion tensor magnetic resonance imaging}

Diffusion tensor imaging (DTI), derived from DWI, measures the degree and direction of water diffusion (anisotropy). Water diffusion anisotropy reflects the integrity of white matter tracts. Pathophysiological mechanisms that can alter water diffusion anisotropy include DAl, effects of intracranial hypertension and disconnection of white matter tracts.

\section{Magnetization transfer imaging}

This sequence is based on the principle that structure-bound protons undergo $\mathrm{T} 1$ relaxation coupling with protons in the aqueous phase. Saturated protons in macromolecules exchange longitudinal magnetization with protons in the aqueous phase, leading to a reduction in signal intensity. Magnetization transfer imaging has been found to be sensitive for detecting white matter lesions in several neurological conditions $[11,12]$.
Figure 1

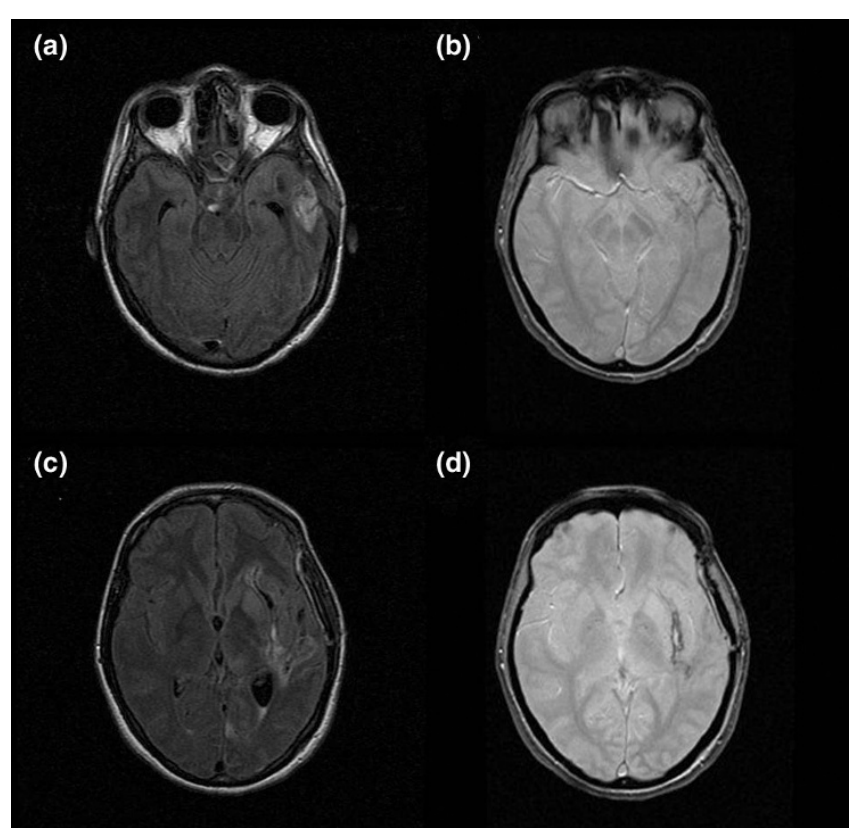

FLAIR and T2* sequences in a patient with an arteriovenous malformation. (a) Axial fluid-attenuated inversion recovery (FLAIR) sequence showing hypersignal in the left temporal lobe. (b) Axial T2* sequence showing mild hyposignal in the same area suggestive of bleeding. (c) Different section of the axial FLAIR sequence showing hypersignal surrounded by hyposignal. Bleeding cannot be confirmed. (d) Axial T2* sequence clearly showing hyposignal lateral to the left putamen. The patient has bleeding from the arteriovenous malformation.

\section{Functional magnetic resonance imaging}

Functional MRI may reveal foci of cerebral dysfunction in regions that look structurally intact on conventional MRI. Imaging is based on changes in the oxidative state of haemoglobin, which reflects regional brain activation. Functional MRI remains difficult to perform in critically ill unstable patients and, consequently, few teams have acquired the equipment and experience necessary to apply this technique [13]. The few available studies conducted in comatose patients with TBI showed a correlation between prefrontal/cingulated cortical activation disturbation and cognitive impairments [14,15]. However, functional MRI was performed in these studies at a distance from the injury.

\section{Magnetic resonance imaging findings in specific critical neurological conditions}

\section{Traumatic brain injury}

Conventional magnetic resonance imaging

MRI was first used to investigate patients with TBI in a 1986 study of 50 patients [16]. The three main findings, which have since been confirmed, were as follows: MRI identified lesions more frequently than did computed tomography; brain lesions were common after TBI; and although patients who regained consciousness rapidly had no lesions in fundamental deep 
(a)

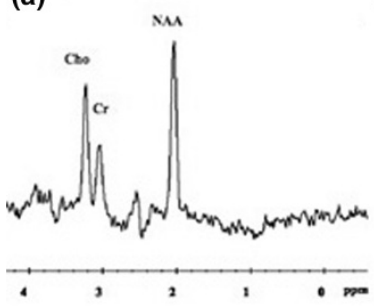

(b)

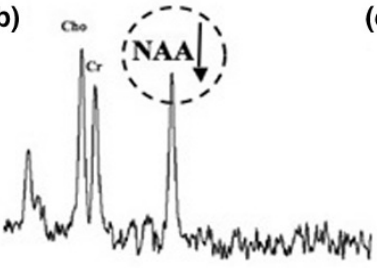

(c)

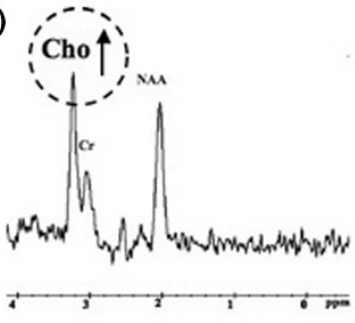

Magnetic resonance spectroscopy profile of the pons after traumatic brain injury. (a) Normal profile. The peak of $\mathrm{N}$-acetyl-aspartate (NAA) is higher than the peaks of choline (Cho) and creatine (Cr). (b) Neuronal loss profile. The NAA peak is decreased, nearly to the level of the Cr peak. The NAA/Cr ratio is lower than in panel a. (c) Gliosis profile: increased Cho peak with no change in the Cr or NAA peak. Adapted from [17].

brain structures, some of them had severe cortical lesions. Several descriptions of MRI lesions in TBI patients have been reported since that initial study was published (Table 1 ) [17-21], although few of them focused on the prognostic value of MRI [17-20]. Conventional MRI findings that strongly predicted outcome included DAI, total lesion burden and DAI in the brainstem.

DAI is the most common primary lesion in TBI patients [22,23] and may be the most common cause of poor outcome [22-24]. DAl may be ischaemic or haemorrhagic $[7,8]$. Ischaemic DAI is seen as a hypersignal on DWI or FLAIR, with no abnormality on the T2* sequence [25]. The hypersignal with DWI disappears within about 2 weeks. Conversely, haemorrhagic DAl appears as a hyposignal on the $\mathrm{T}^{*}$ sequence, with normal DWI findings. It has been proposed [22] that DAI location could be classified into the following stages: stage 1, frontal and temporal white matter; stage 2, lobar white matter and posterior part of corpus callosum; and stage 3, dorsolateral midbrain and pons. With outcomes defined as Glasgow Outcome Scale [26] scores of 2 to 3 versus 4 to 5 , none of the 33 patients with good outcome in another study [27] had haemorrhagic DAl (Table 1). DAl appears to be a major determinant of poor outcomes, although its use as an outcome predictor in the individual patient remains difficult. Whether the correlation between DAl and outcome is due to the total lesion burden or to DAl location remains debated.

In several prospective studies, lesion burden was associated with outcome irrespective of DAl location (Table 1) $[17,19,28]$. Among 40 prospectively enrolled patients with severe TBI, lesions by FLAIR and T2*-weighted sequences increased progressively with GOS score groups 1 to 2, 3, and 4 to 5 [17]. Similar results were obtained in a study comparing 42 patients with persistent vegetative state with 38 patients who recovered consciousness [19].

A number of studies have focused on the value of DAl location in predicting outcome [19,29-31]. Brainstem lesions in the pons and mesencephalon appear to be the most potent markers of poor prognosis, most notably when they are bilateral and symmetrical $[18,19,29,31]$. In a prospective study conducted in 61 patients (Table 1) who were studied within 7 days of TBI [18], all patients with bilateral pontine lesions died as compared with $9 \%$ of patients with no brainstem lesions. These results were confirmed by the same group in a prospective study of 102 comatose patients [29] using the following four-stage grading system: grade I, lesions of the hemispheres only; grade II, unilateral lesions of the brainstem at any level with or without supratentorial lesions; grade III, bilateral lesions of the mesencephalon with or without supratentorial lesions; and grade IV, bilateral lesions of the pons with or without any of the lesions of lesser grades. Mortality increased gradually from 14\% with grade I lesions to $100 \%$ with grade IV lesions. These findings were corroborated by two independent studies [19,31] (Table 1). We recently confirmed the prognostic value of brainstem lesions in the upper pons and lower midbrain in a study of 73 patients [32]. Bilateral pontine lesions carry a high mortality rate and predict poor neurological outcomes.

Three studies showed that corpus callosum lesions were associated with poor outcomes [19,30,31] (Table 1). However, these lesions may merely represent markers for severe initial injury. In addition to lesion burden, both total lesion volume and frontal lobe lesion volume on FLAIR images correlated significantly with clinical outcomes [30]. Nevertheless, evaluating DAI lesion volume is difficult (most notably when the lesions are small), time consuming, cumbersome and subject to inter-rater variability.

The presence of severe DAI and a heavy lesion burden are associated with permanent neurological impairment. However, these factors are difficult to use in the individual patient, especially to distinguish GOS score 2 from GOS score 3. In TBI patients, brainstem lesions are easily identified by MRI. In our experience, they are associated with poor outcomes, most notably when they are posterior and bilateral. 


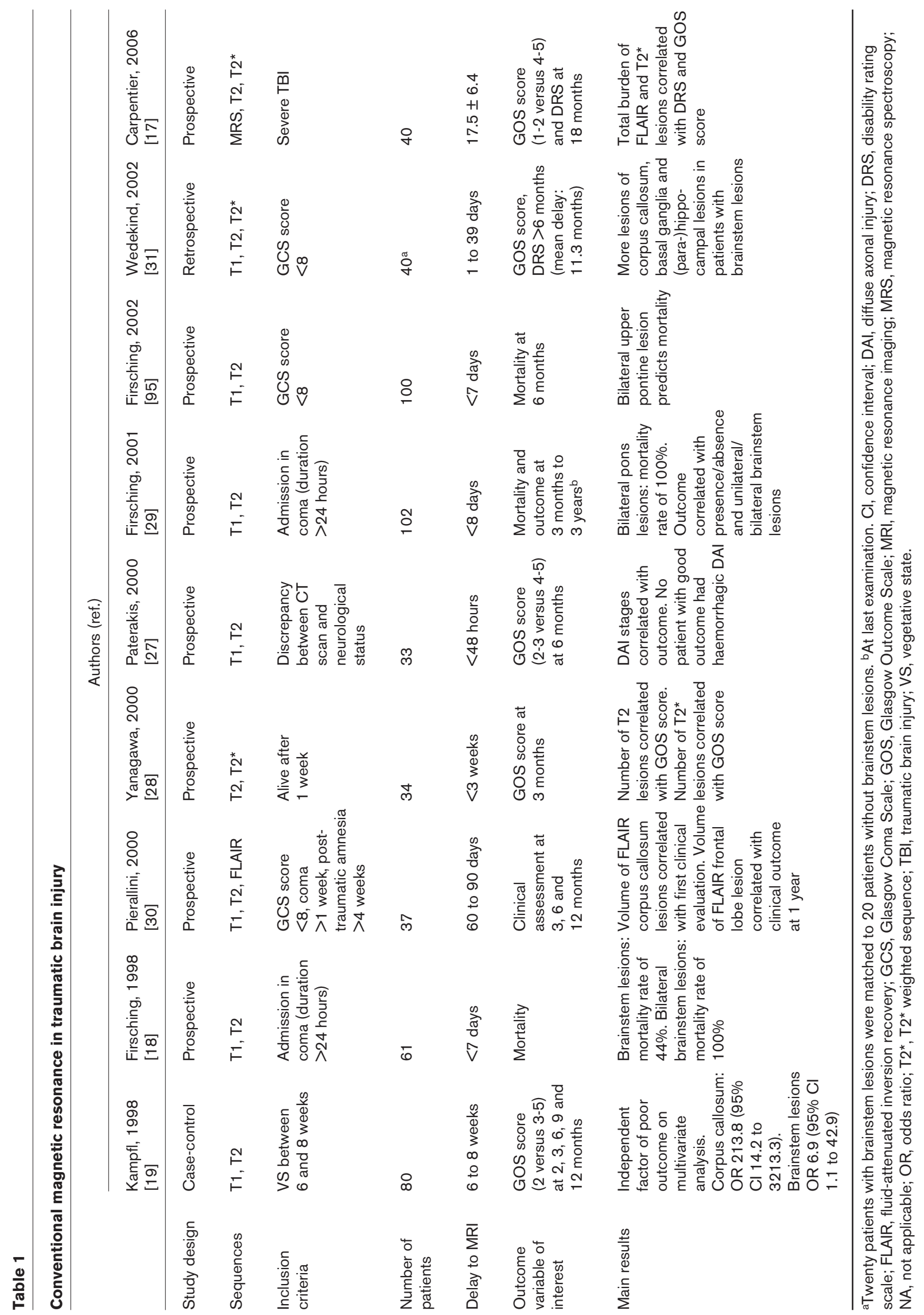


Posterior brainstem lesions in the periaqueductal grey matter are probably more relevant than anterior brainstem lesions as predictors of poor outcomes in patients with brainstem stroke [21] or TBI [19]. In clinical practice, treatment limitation may deserve consideration in patients who have large bilateral lesions in the posterior part of the pons after TBI.

Magnetic resonance spectroscopy

Several MRS studies have been conducted in TBI patients (Table 2). Some of them were purely descriptive [33], others assessed only the neuropsychological outcomes [34,35], and yet others focused on global outcome as evaluated using the GOS or Disability Rating Scale [17,36-42].

Compared with control individuals, TBI patients exhibited decreased NAA levels, decreased NAA/creatine ratios and increased choline levels (Table 2) in all brain regions evaluated [35-39,41,42]. Increased lactate levels were seldom found in TBI patients, contrary to patients with other brain injuries [38]. The NAA/creatine ratio appeared to be the best outcome predictor. Low NAA/creatine values correlated with poor outcomes when they were located in the frontal [37,39], frontoparietal [43], or occipitoparietal lobes [36,40]; the splenium of the corpus callosum [41]; the thalami [42]; the pons [17]; or a voxel including the corpus callosum, the white matter, and part of the hemispheric cortex [38].

These studies are heterogeneous (Table 2) in terms of patient selection, time from TBI to MRS, voxel location, method of outcome assessment and timing of outcome assessment. For instance, among studies of patients with TBI, one included only patients in a vegetative state [42], another included patients with severe TBI [17] and a third excluded patients with early initial coma [36]. These differences in patient selection may be associated with differences in severity of brain oedema and in associated hypoxia and herniation, thereby introducing bias into the interpretation of the results. MRS findings vary greatly according to time since TBI. Four phases may be distinguished: an acute phase, which lasts 24 hours after $\mathrm{TBI}$; an early subacute phase, which spans from the days 1 to 13; a late subacute phase, from days 14 to 20; and a chronic phase, which starts on day 21. Only two studies included patients at the acute phase $[38,40]$, and only one of these included all patients before 72 hours [38]. Two studies were conducted from the early subacute phase to the first month $[17,37]$ and one began inclusion in the late subacute phase but included patients up to 11 months after TBI [43]. Four studies focused on the chronic phase; in two of these studies, patients were included 3 weeks to 6 months after TBI $[36,39]$ and in the other two studies they were included 2 months to 8 months after TBI $[39,42]$.

Although NAA/creatine ratios were similar across studies, the results should be interpreted with caution because experimental in vitro and in vivo data suggest differences in the underlying pathophysiological mechanisms and in the time course of the lesions [44-46]. To interpret these results reliably, information on NAA values over time are needed. Experiments conducted in vitro [44] and in vivo $[45,46]$ show an early NAA decrease starting within a few minutes after TBI and reaching the trough value within 48 hours. This finding explains why spectroscopic disturbances may require 48 hours for visualization [47]. NAA levels remain stable within the first month after $\mathrm{TBI}$, supporting the validity of MRS assessment during the second or third week $[48,49]$. Later on, between 6 weeks and 1 year after TBI, NAA levels may decrease [9,37]. Partial recovery of NAA levels has been suggested and may indicate recovery of mitochondrial function [41].

Another important factor that varied across studies was MRS voxel location (Table 2). Voxels were located in the hemisphere (the occipitoparietal, frontoparietal, or frontal lobes), corpus callosum, thalamus, or brainstem (the pons). Because whole brain analysis is time consuming, voxels are typically restricted to the areas most affected by DAl, namely the lobar white matter, corpus callosum and upper brainstem [50]. Estimation of NAA in the whole brain may improve the prognostic value of MRS [41]. A good compromise may be a voxel encompassing the corpus callosum, white matter and part of the hemispheric cortex [38].

Studies also differed in their definitions of poor and good GOS outcome groups: comparisons involved GOS score 1 to 2 versus GOS score 3 to 5 [39], GOS score 1 to 4 versus GOS score 5 [41], or GOS score 1 to 2 versus GOS score 4 to 5 [17]. Finally, the time from TBI to outcome assessment varied from 3 to 18 months (Table 2), further complicating comparisons because neurological status may improve for up to 1 year after TBI.

Although MRS has superseded conventional MRI, the combination of these two techniques may be useful [17]. Variations in the NAA/creatine ratio over time have not been studied in a large TBI patient population. The above-mentioned variability in NAA levels constitutes the main limitation of this technique. To overcome this limitation, repeated studies at intervals of 1 to 2 weeks are probably needed. In our experience, variations in the NAA/creatine ratio are minimal in many patients. We agree with Sinson and coworkers [41] that whole brain NAA estimation might improve the prognostic value of MRS. Absence of dysfunction by MRS is a valuable finding; in a patient with normal results by both conventional MRI and MRS, a poor outcome is unlikely. However, we have seen a few patients with normal conventional MRI and MRS findings who had poor outcomes, probably related to white matter damage detected as DTI abnormalities.

Diffusion tensor magnetic resonance imaging

Initial reports of DTI in TBI patients suggest that this technique may demonstrate alterations in white matter connections that are missed by conventional MRI [51]. DTI provides information on the physiological status of fibre 


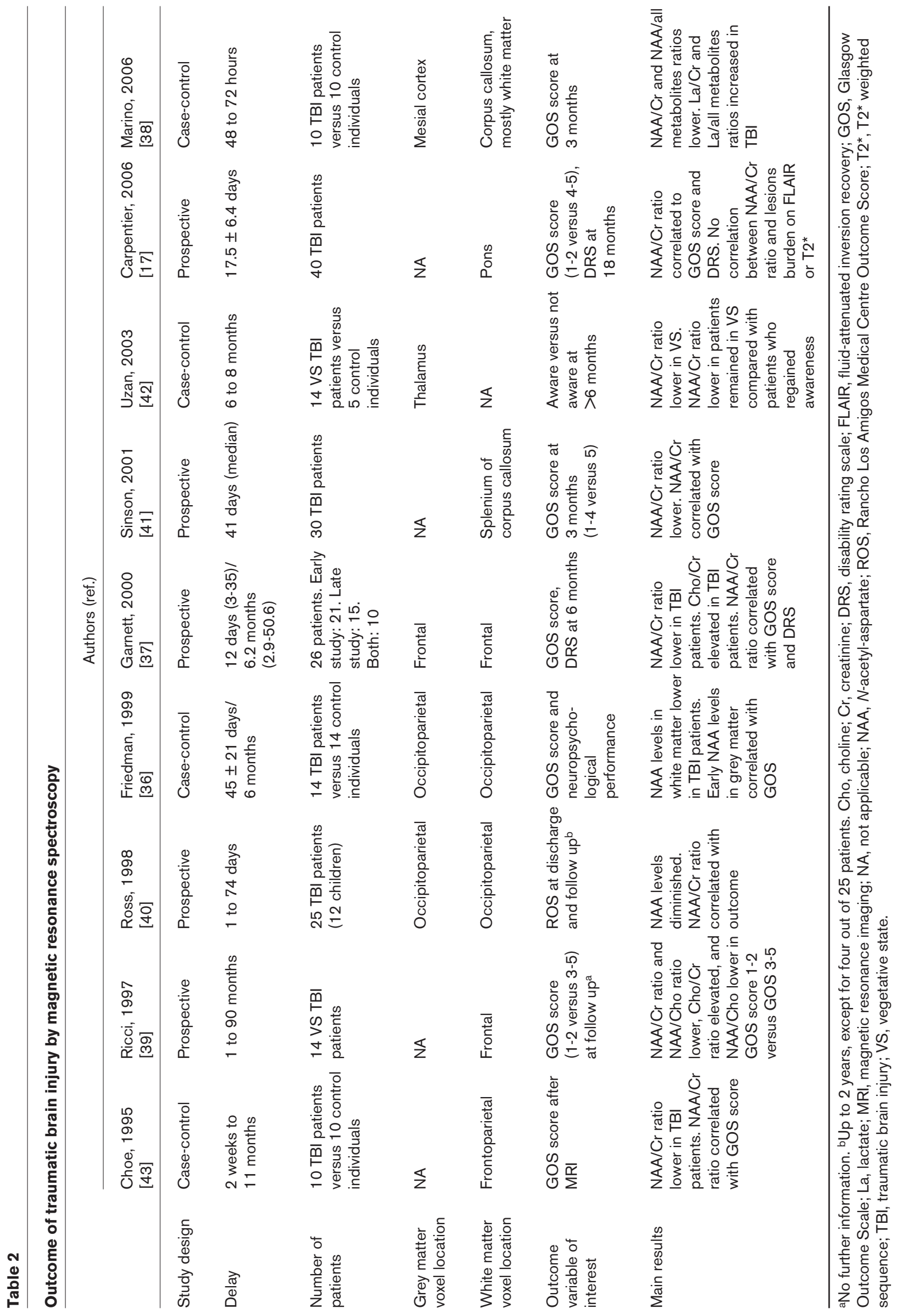


bundles, thus complementing the metabolic and biochemical information supplied by MRS. At present, little is known about the prognostic value of DTI in patients with TBI. DTI findings correlated with clinical status in patients with multiple sclerosis or neurodegenerative disease [52,53]. In a mouse model of TBI, DTI parameters were significantly reduced in the injured brain, whereas conventional MRI showed no significant changes [54]. Furthermore, changes in relative anisotropy correlated significantly with the density of stained axons on histological sections.

In a study comparing $20 \mathrm{TBI}$ patients and 15 healthy control individuals, fractional anisotropy was reduced in the internal capsule and splenium of the corpus callosum and correlated with Glasgow Coma Scale score and Rankin score at discharge in the TBI patients [55]. Similar findings have been reported in children [56]. Anecdotal case reports of DTI abnormalities in TBI patients have been reported $[57,58]$. In two patients who recovered partially after 6 years and 19 years, respectively, in a minimally conscious state, DTI disclosed increased anisotropy within the midline cerebellar white matter over an 18-month period [59]. This anisotropy increase correlated with an increase in resting metabolism, measured using positron emission tomography, which suggests that axonal regrowth might underlie increases in anisotropy. Larger studies of DTI variations over time are needed. In our institution, comatose patients have been included in a prospective DTI study for the past 3 years. Patients with major connectivity abnormalities in both hemispheres and the brainstem were at increased risk for poor outcomes. A large multicentre prospective study is ongoing in France to assess the usefulness of combining DTI with MRS.

\section{Magnetization transfer imaging}

Magnetization transfer imaging is sensitive for detecting white matter lesions in patients with multiple sclerosis, progressive multifocal leukoencephalopathy, or wallerian degeneration $[11,12]$. Preliminary results in TBI are promising $[60,61]$. The magnetization transfer ratio was decreased in TBI patients $[60,61]$. Out of $28 \mathrm{TBI}$ patients, eight had abnormal magnetization transfer ratios, and all eight had persistent neurological deficits [62]. In another study, however, no correlation was found between GOS score and abnormal magnetization transfer ratio [41].

\section{Anoxic/hypoxic encephalopathy}

Anoxic/hypoxic encephalopathy is a devastating condition; its development after prolonged cerebral hypoxia is often difficult to predict on clinical grounds. No controlled studies of routine MRI in large numbers of cardiac arrest patients have been reported. Anecdotal case reports and small series are available [63-67]. As with TBI, MRI findings in hypoxic/anoxic encephalopathy go through four phases [66]: an acute phase, which lasts 24 hours after anoxia or hypoxia; an early subacute phase, from days 1 to 13 ; a late subacute phase, from days 14 to 20; and a chronic phase, starting on day 21. MRI findings in patients with hypoxic brain damage are complex but distinctive. Brain swelling, cortical laminar necrosis, hypersignal of basal ganglia, delayed white matter degeneration and atrophy occur in succession, as shown in Table $3[63,66,67]$. During the acute and early subacute phases, DWI and T2-weighted sequence show hypersignals in the cortex, thalamus and basal ganglia. DWI may be more sensitive for detecting mild hypoxic/anoxic injury within the first few hours, and the hypersignal may occur first in the cerebral cortex and later in the basal ganglia. During the late subacute phase the hypersignals previously seen by DWI tend to fade, and diffuse white matter abnormalities denoting delayed anoxic leukoencephalopathy may develop [68]. During the chronic phase diffuse atrophy and dilatation of the ventricles are visible, whereas DWI is normal.

The three main series published to date included ten [66], eight [67] and six [63] patients. Although the small numbers of patients is a limitation, the succession of four phases was confirmed in several case reports and supported by findings of histological and animal studies [9,12,16,67], indicating far greater vulnerability of grey matter to hypoxia as compared with white matter. This difference in vulnerability may explain why some brain regions are more susceptible than others to diffuse insults such as hypoxia or anoxia $[2,11,29,66]$.

A few studies recorded both MRI findings and long-term outcomes in patients with hypoxic/anoxic encephalopathy $[64,67,69]$. Diffuse cortical abnormalities by DWI in the acute or early subacute phase appear to be of unfavourable prognostic significance. Of six patients with hypoxic encephalopathy investigated by sequential MRI, the only patient who recovered a GOS score greater than 3 had hypersignals in watershed zones in the parieto-occipito-temporal cortex without cortical hypersignal by DWI. In a study of 10 patients who had suffered a cardiac arrest, FLAIR and DWI showed that eight patients had diffuse abnormalities in the cerebellum, thalamus, frontal and parietal cortices, and hippocampus [69]. None of the patients with cortical structure abnormalities recovered beyond a severely disabled state. In another prospective study, the prognostic value of DWI was evaluated in 12 patients within 36 hours after global cerebral hypoxia [64]. DWI findings correlated with clinical outcomes after 6 months. The three patients with short resuscitation times had a good recovery and normal DWI findings. Of the remaining nine patients, all had DWI abnormalities and developed a vegetative state. Thus, diffuse cortical hypersignals by DWI appear to predict a poor outcome. Conversely, several reports describe delayed anoxic encephalopathy with a good final outcome and resolution of MRI abnormalities. Therefore, finding diffuse hypersignals in the white matter by either DWI or T2/FLAIR weighted sequences should not lead to treatment limitation decisions. In general, whether MRI findings can be used to guide treatment limitation decisions remains unclear. In our unit, 
Table 3

\begin{tabular}{|c|c|c|c|c|}
\hline & $\begin{array}{l}\text { Acute phase } \\
(<24 \text { hours })\end{array}$ & $\begin{array}{l}\text { Early subacute phase } \\
\text { ( } 24 \text { hours to day } 13)\end{array}$ & $\begin{array}{l}\text { Late subacute phase } \\
\text { (days } 14 \text { to } 20 \text { ) }\end{array}$ & $\begin{array}{l}\text { Chronic phase } \\
(>21 \text { days })\end{array}$ \\
\hline Characteristics & Brain swelling & Brain swelling & Absence of brain swelling & $\begin{array}{l}\text { Diffuse atrophy and } \\
\text { dilatation of the ventricles }\end{array}$ \\
\hline DWI & $\begin{array}{l}\text { Hypersignals in the cortex, } \\
\text { in the thalamus and in the } \\
\text { basal ganglia }\end{array}$ & $\begin{array}{l}\text { Hypersignals in the cortex, } \\
\text { in the thalamus and in the } \\
\text { basal ganglia }\end{array}$ & $\begin{array}{l}\text { Progressive disappearance } \\
\text { of hypersignals found } \\
\text { previously }\end{array}$ & Normal \\
\hline T2 & $\begin{array}{l}\text { Hypersignals in the cortex, } \\
\text { in the thalamus and in the } \\
\text { basal ganglia }\end{array}$ & $\begin{array}{l}\text { Hypersignals in the cortex, } \\
\text { in the thalamus and in the } \\
\text { basal ganglia. Possible } \\
\text { subcortical hyposignals }\end{array}$ & $\begin{array}{l}\text { Hypersignals of the cortex, } \\
\text { the thalamus, the basal ganglia } \\
\text { and the pons }\end{array}$ & $\begin{array}{l}\text { Normal or possible } \\
\text { hypersignals of the cortex, } \\
\text { the thalamus, the basal } \\
\text { ganglia and the pons }\end{array}$ \\
\hline T1 & No abnormalities & No abnormalities & $\begin{array}{l}\text { Possible spontaneous } \\
\text { subcortical and basal ganglia } \\
\text { hypersignals }\end{array}$ & Can be normal \\
\hline $\begin{array}{l}\text { T1 with } \\
\text { gadolinium } \\
\text { enhancement }\end{array}$ & No abnormalities & $\begin{array}{l}\text { Possible subcortical } \\
\text { enhancement suggestive of } \\
\text { cortical laminar necrosis }\end{array}$ & $\begin{array}{l}\text { Possible subcortical } \\
\text { enhancement suggestive of } \\
\text { cortical laminar necrosis }\end{array}$ & No abnormalities \\
\hline Comments & $\begin{array}{l}\text { DWI seems more sensitive } \\
\text { to mild hypoxic/anoxic injury } \\
\text { in the first hours, and the } \\
\text { hypersignal in cerebral } \\
\text { cortex seems more } \\
\text { precocious than in the basal } \\
\text { ganglia }\end{array}$ & $\begin{array}{l}\text { Hypersignals on both DWI and } \\
\text { T2 become more intense, } \\
\text { particularly in the thalamus and } \\
\text { the basal ganglia }\end{array}$ & $\begin{array}{l}\text { In some cases, appearance of } \\
\text { diffuse white matter, } \\
\text { abnormalities of delayed anoxic } \\
\text { leukoencephalopathy on both } \\
\text { DWI and T2 }\end{array}$ & $\begin{array}{l}\text { In some cases, } \\
\text { hypersignals of the cortex } \\
\text { and hyposignals in the } \\
\text { subcortical zone on both } \\
\text { T2 and T1, suggestive of } \\
\text { cortical laminar necrosis }\end{array}$ \\
\hline
\end{tabular}

DWI, diffusion weighted imaging; T1, T1 weighted sequence; T2, T2 weighted sequence. Adapted from $[66,67]$.

treatment limitation is considered in patients with diffuse cortical hypersignals by DWI or cortical laminar necrosis images after prolonged cardiac arrest, provided the MRI findings are consonant with the clinical examination or electrophysiological data. In contrast, a patient with normal MRI findings after anoxia should probably be re-evaluated 1 or 2 weeks later by clinical examination, electrophysiological testing and MRI.

Few data are available on MRS findings after anoxia [70,71]. No studies were specifically designed to assess the prognostic value of DTI in patients with anoxic/hypoxic encephalopathy. The unique ability of DTI to distinguish between white matter and grey matter, allowing separate quantitative assessment of these two tissues, should be of particular interest in anoxic/hypoxic encephalopathy.

Severe hypoglycaemia has been likened to hypoxic encephalopathy. Imaging study data in patients with hypoglycaemic coma are scant $[63,72,73]$. Interestingly, DWI abnormalities can mimic stroke in patients with hypoglycaemic coma $[74,75]$. Rapid improvements in DWI and MRI abnormalities after glucose infusion were recently reported [76].

\section{Ischaemic stroke}

Ischaemic stroke causes coma in two main settings, namely malignant stroke and basilar artery occlusion. We focus on these two situations, and we do not discuss the prognostic value of MRI after stroke without coma.

In a study of 37 patients with acute middle cerebral artery infarction, early quantitative DWI findings predicted progression to malignant stroke, which occurred in 11 patients [77]. Factors that predicted malignant stroke were as follows: size of the region with apparent diffusion coefficient $(A D C)<80 \%$ greater than $82 \mathrm{ml}$; ADC in the core of the stroke $<300 \mathrm{~mm}^{2} / \mathrm{s}$; and relative ADC within the ADC $<80 \%$ of the lesion under 0.62 . Another study evaluated 28 patients, of whom 11 experienced malignant stroke [78]. The best predictor of malignant stroke within 14 hours of stroke onset was infarct volume by DWI greater than $145 \mathrm{~cm}^{3}$, which was $100 \%$ sensitive and $94 \%$ specific. Regarding brainstem stroke, a retrospective study of 47 patients showed that coma, which was a feature in nine patients, was associated with lesions in the posterior pons and lower midbrain [21]. The patients who died had all bilateral brainstem lesions in this area. None of the patients with bilateral lesions survived. Although the number of patients was small in the study, the results are consonant with clinical experience that brainstem stroke with coma and large brainstem lesions has a poor outcome and that some patients who are initially comatose with limited anterior brainstem infarction eventually experience good outcomes. 
DTI has been used to assess outcomes after stroke [79], although we are not aware of studies of MRS or DTI to predict outcomes after malignant or brainstem stroke. In a study of 12 patients with subcortical infarcts involving the posterior limb of the internal capsule, a decrease in fractional anisotropy was detected by DTI, indicating secondary degeneration of the fibre tract proximal and distal to the primary ischaemic lesion [80]. Fibre tract degeneration occurred gradually, which might have hampered functional recovery. In patients with brainstem stroke or malignant stroke, DTI may be of considerable value for assessing fibre tract degeneration, thus predicting chances of recovery.

\section{Ascending reticular activating system and prognosis of brain injuries}

Several brain areas involved in the prognosis of TBI or stroke play a role in consciousness $[17,19,21,81]$. Figure 3 shows the anatomical regions involved in arousal and consciousness. Brainstem lesions have been shown to influence the prognosis of patients with coma after TBI or stroke $[17,19,21,81]$. Bilateral brainstem lesions were associated with poorer outcomes [21,81], and the target area appeared to be the posterior pons and lower midbrain, where the ascending reticular activating system (ARAS) nuclei are located. An MRI study of 88 patients in a vegetative state after TBI confirmed the prognostic importance of lesions in this area [19]. The ARAS projects in part to the basal forebrain through the hypothalamus by its ventral pathway, as shown in Figure 3. Several pathological studies showed a high rate of basal forebrain lesions in humans who died after head injuries [82], and we found that hypothalamic and basal forebrain lesions were associated with poor outcomes in TBI patients [32]. Histological evidence of neuronal damage in the nucleus basalis of Meynert (the main nucleus of the basal forebrain) was found in most of the patients who died after head injury [82]. The ARAS projects to the reticular thalamic nuclei through its dorsal pathway (Figure 3). Focal damage to the thalami was documented in pathological studies of patients in vegetative state $[83,84]$. All three pathways lead to cortical arousal. Widespread cortical damage (as described in anoxic/hypoxic encephalopathy $[83,85]$ ) and widespread white matter damage (as described in TBI patients [86]) may result in inability to arouse cortical areas (vegetative state). Clinical findings in patients with $\mathrm{TBI}$ suggest that impairment in consciousness may correlate with depth of the deepest lesion $[20,87]$. Although lesions to the ARAS or its projections may correlate with severity of the initial injury or the existence of herniation, another possibility is that they directly contribute to the prognosis. Studies involving multimodal investigations would provide valuable insight in this area [88].

\section{Avenues for research}

Data from patients with TBI, stroke, or anoxic encephalopathy suggest that specific MRI findings may hold promise for outcome prediction. Large studies are not yet available, even

\section{Figure 3}

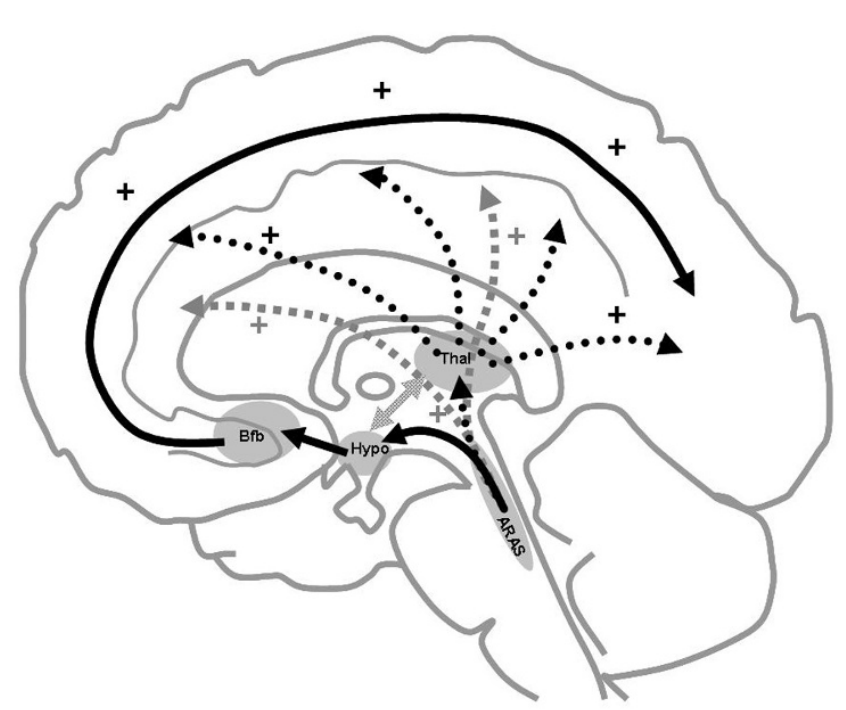

Anatomical substratum of arousal and awareness. Consciousness involves two main components: arousal and awareness of oneself and of the environment. Awareness is dependent on the integrity of specific anatomical regions [89]. The ascending reticular activating system (ARAS), the primary arousal structure, is located in the upper pons and lower midbrain in the posterior part of the upper two-thirds of the brainstem [90,91]. A ventral pathway (black solid arrows) projects to the hypothalamus (hypo) and basal forebrain (Bfb); a dorsal pathway (black dashed arrows) projects to the reticular nuclei of the thalamus (thal); and a third pathway (light grey arrows) projects directly into the cortical regions [90]. From the basal forebrain, two main bundles project diffusely to several cortical areas [92]. The reticular nuclei of the thalamus connect to other nuclei in the thalamus. They are involved in a thalamo-cortical circuit [93] that controls cortical activity. Some regions of the cerebral cortex may also make specific contributions to consciousness [94].

in patients with TBI. Given the major ethical, human and economic issues involved, there is an urgent need for large prospective multicentre studies. Only small numbers of patients eligible for such studies are admitted to medical or surgical intensive care units, and few neurosurgical or neurological intensive care units exist; therefore, a multicentre design is essential to ensure recruitment of a sufficiently large population. In our institution, which is a neurosurgical intensive care unit in a tertiary hospital, multimodal prospective imaging by conventional MRI, MRS and DTI is performed routinely in all patients who are still comatose after 2 weeks. A multicentre study funded by the French Ministry of Health is under way.

\section{Conclusion}

Patients with severe brain injury, most notably those who remain comatose, generate huge health care costs. Adapting the level of medical care to the neurological outcome is a major challenge currently faced by neurological intensive care. Meeting this challenge will require the development of tools that reliably predict long-term neurological outcomes. 
Most MRI studies to date were conducted in patients with TBI. By conventional imaging, presence of bilateral lesions in the dorsolateral upper brainstem appears to be the factor of greatest adverse prognostic significance. With MRS, low NAA/creatine ratio in the hemispheres and in the pons predicts a poor outcome. In anoxic/hypoxic encephalopathy, the factor of greatest adverse significance appears to be the presence of diffuse cortical abnormalities by DWI. However, data are scarcer than in the field of TBI. Finally, regarding brainstem stroke, posterior lesions appear to be associated with poor outcome.

The prognostic value of imaging studies could be improved by combining several techniques and sequences, for instance by combining several MRI sequences or by combining MRI with electrophysiological studies or clinical data. Complete destruction of arousal structures is consistently associated with poor outcome. Multimodal MRI is a promising technique that can be expected to provide accurate prediction of neurological outcome in the near future.

\section{Competing interests}

The authors declare that they have no competing interests.

\section{References}

1. Oddo M, Schaller MD, Feihl F, Ribordy V, Liaudet L: From evidence to clinical practice: effective implementation of therapeutic hypothermia to improve patient outcome after cardiac arrest. Crit Care Med 2006, 34:1865-1873.

2. Celesia GG: Persistent vegetative state. Neurology 1993, 43: 1457-1458.

3. Jennett B: Thirty years of the vegetative state: clinical, ethical and legal problems. Prog Brain Res 2005, 150:537-543.

4. Payne K, Taylor RM, Stocking C, Sachs GA: Physicians' attitudes about the care of patients in the persistent vegetative state: a national survey. Ann Intern Med 1996, 125:104-110.

5. Anderson CV, Wood DM, Bigler ED, Blatter DD: Lesion volume, injury severity, and thalamic integrity following head injury. $J$ Neurotrauma 1996, 13:35-40.

6. Brandstack N, Kurki T, Tenovuo O, Isoniemi H: MR imaging of head trauma: visibility of contusions and other intraparenchymal injuries in early and late stage. Brain Inj 2006, 20:409-416.

7. Gerber DJ, Weintraub AH, Cusick CP, Ricci PE, Whiteneck GG: Magnetic resonance imaging of traumatic brain injury: relationship of T2*SE and T2GE to clinical severity and outcome. Brain Inj 2004, 18:1083-1097.

8. Scheid R, Preul C, Gruber O, Wiggins C, von Cramon DY: Diffuse axonal injury associated with chronic traumatic brain injury: evidence from $\mathrm{T2}^{*}$-weighted gradient-echo imaging at 3 T. AJNR Am J Neuroradio/ 2003, 24:1049-1056.

9. Brooks WM, Friedman SD, Gasparovic C: Magnetic resonance spectroscopy in traumatic brain injury. J Head Trauma Rehabil 2001, 16:149-164.

10. Garnett MR, Cadoux-Hudson TA, Styles P: How useful is magnetic resonance imaging in predicting severity and outcome in traumatic brain injury? Curr Opin Neurol 2001, 14:753-757.

11. Filippi M, Rocca MA: Magnetization transfer magnetic resonance imaging in the assessment of neurological diseases. $J$ Neuroimaging 2004, 14:303-313.

12. Horsfield Ma: Magnetization transfer imaging in multiple sclerosis. J Neuroimaging 2005, Suppl:58S-67S.

13. Pickard JD, Hutchinson PJ, Coles JP, Steiner LA, Johnston AJ, Fryer TD, Coleman MR, Smielewski P, Chatfield DA, Aigbirhio F, et al.: Imaging of cerebral blood flow and metabolism in brain injury in the ICU. Acta Neurochir Supp/ 2005, 95:459-464.

14. Azouvi P: Neuroimaging correlates of cognitive and functional outcome after traumatic brain injury. Curr Opin Neurol 2000, 13:665-669.
15. Fontaine A, Azouvi $P$, Remy $P$, Bussel B, Samson Y: Functional anatomy of neuropsychological deficits after severe traumatic brain injury. Neurology 1999, 53:1963-1968.

16. Jenkins A, Teasdale G, Hadley MD, Macpherson P, Rowan JO: Brain lesions detected by magnetic resonance imaging in mild and severe head injuries. Lancet 1986, 2:445-446.

17. Carpentier A, Galanaud D, Puybasset L, Muller JC, Lescot T, Boch AL, Riedl V, Cornu P, Coriat P, Dormont D, et al.: Early morphologic and spectroscopic magnetic resonance in severe traumatic brain injuries can detect 'invisible brain stem damage' and predict 'vegetative states'. J Neurotrauma 2006, 23:674-685.

18. Firsching R, Woischneck D, Diedrich M, Klein S, Ruckert A, Wittig $\mathrm{H}$, Dohring W: Early magnetic resonance imaging of brainstem lesions after severe head injury. J Neurosurg 1998, 89:707712.

19. Kampfl A, Schmutzhard E, Franz G, Pfausler B, Haring HP, Ulmer $\mathrm{H}$, Felber S, Golaszewski S, Aichner F: Prediction of recovery from post-traumatic vegetative state with cerebral magneticresonance imaging. Lancet 1998, 351:1763-1767.

20. Levin HS, Mendelsohn D, Lilly MA, Yeakley J, Song J, Scheibel RS, Harward H, Fletcher JM, Kufera JA, Davidson KC, Bruce D: Magnetic resonance imaging in relation to functional outcome of pediatric closed head injury: a test of the OmmayaGennarelli model. Neurosurgery 1997, 40:432-440; discussion 440-441.

21. ParviziJ, Damasio AR: Neuroanatomical correlates of brainstem coma. Brain 2003, 126:1524-1536.

22. Gentry LR: Imaging of closed head injury. Radiology 1994, 191: 1-17.

23. Parizel PM, Ozsarlak, Van Goethem JW, van den Hauwe L, Dillen C, Verlooy J, Cosyns P, De Schepper AM: Imaging findings in diffuse axonal injury after closed head trauma. Eur Radiol 1998, 8:960-965.

24. Wilberger JE Jr, Deeb Z, Rothfus W: Magnetic resonance imaging in cases of severe head injury. Neurosurgery 1987 , 20:571-576.

25. Huisman TA: Diffusion-weighted imaging: basic concepts and application in cerebral stroke and head trauma. Eur Radiol 2003, 13:2283-2297.

26. Jennett $B$, Bond $M$ : Assessment of outcome after severe brain damage. Lancet 1975, 1:480-484.

27. Paterakis $\mathrm{K}$, Karantanas AH, Komnos A, Volikas Z: Outcome of patients with diffuse axonal injury: the significance and prognostic value of MRI in the acute phase. J Trauma 2000, 49: 1071-1075.

28. Yanagawa $Y$, Tsushima $Y$, Tokumaru A, Un-no $Y$, Sakamoto $T$, Okada $Y$, Nawashiro $H$, Shima K: A quantitative analysis of head injury using $\mathrm{T}^{*}$-weighted gradient-echo imaging. $J$ Trauma 2000, 49:272-277.

29. Firsching R, Woischneck D, Klein S, Reissberg S, Dohring W, Peters B: Classification of severe head injury based on magnetic resonance imaging. Acta Neurochir (Wien) 2001, 143:263-271.

30. Pierallini A, Pantano P, Fantozzi LM, Bonamini M, Vichi R, Zylberman R, Pisarri F, Colonnese C, Bozzao L: Correlation between MRI findings and long-term outcome in patients with severe brain trauma. Neuroradiology 2000, 42:860-867.

31. Wedekind C, Hesselmann V, Lippert-Gruner M, Ebel M: Trauma to the pontomesencephalic brainstem: a major clue to the prognosis of severe traumatic brain injury. $\mathrm{Br} J$ Neurosurg 2002, 16:256-260.

32. Weiss N, Galanaud D, Carpentier A, Tezenas de Montcel S, Naccache L, Coriat P, Puybasset L: A combined clinical and MRI approach for outcome assessment of traumatic head injured comatose patients. J Neurol 2007, in press.

33. Cecil KM, Hills EC, Sandel ME, Smith DH, Mclntosh TK, Mannon LJ, Sinson GP, Bagley LJ, Grossman RI, Lenkinski RE: Proton magnetic resonance spectroscopy for detection of axonal injury in the splenium of the corpus callosum of brain-injured patients. J Neurosurg 1998, 88:795-801.

34. Brooks WM, Stidley CA, Petropoulos H, Jung RE, Weers DC, Friedman SD, Barlow MA, Sibbitt WL Jr, Yeo RA: Metabolic and cognitive response to human traumatic brain injury: a quantitative proton magnetic resonance study. J Neurotrauma 2000, 17:629-640.

35. Friedman SD, Brooks WM, Jung RE, Hart BL, Yeo RA: Proton MR spectroscopic findings correspond to neuropsychological 
function in traumatic brain injury. AJNR Am J Neuroradiol 1998, 19:1879-1885.

36. Friedman SD, Brooks WM, Jung RE, Chiulli SJ, Sloan JH, Montoya $B T$, Hart BL, Yeo RA: Quantitative proton MRS predicts outcome after traumatic brain injury. Neurology 1999, 52: 1384-1391.

37. Garnett MR, Blamire AM, Corkill RG, Cadoux-Hudson TA, Rajagopalan B, Styles P: Early proton magnetic resonance spectroscopy in normal-appearing brain correlates with outcome in patients following traumatic brain injury. Brain 2000, 123:2046-2054.

38. Marino S, Zei E, Battaglini M, Vittori C, Buscalferri A, Bramanti P, Federico A, De Stefano N: Acute metabolic brain changes following traumatic brain injury and their relevance to clinical severity and outcome. J Neurol Neurosurg Psychiatry 2007, 78: 501-507.

39. Ricci R, Barbarella G, Musi P, Boldrini P, Trevisan C, Basaglia N: Localised proton MR spectroscopy of brain metabolism changes in vegetative patients. Neuroradiology 1997, 39:313319.

40. Ross BD, Ernst T, Kreis R, Haseler L, Bayer S, Danielsen E, Bluml S, Shonk T, Mandigo JC, Caton W, et al:: 1H MRS in acute traumatic brain injury. J Magn Reson Imaging 1998, 8:829-840.

41. Sinson G, Bagley LJ, Cecil KM, Torchia M, McGowan JC, Lenkinski RE, Mclntosh TK, Grossman Rl: Magnetization transfer imaging and proton MR spectroscopy in the evaluation of axonal injury: correlation with clinical outcome after traumatic brain injury. AJNR Am J Neuroradiol 2001, 22:143-151.

42. Uzan M, Albayram S, Dashti SG, Aydin S, Hanci M, Kuday C: Thalamic proton magnetic resonance spectroscopy in vegetative state induced by traumatic brain injury. J Neurol Neurosurg Psychiatry 2003, 74:33-38.

43. Choe BY, Suh TS, Choi KH, Shinn KS, Park CK, Kang JK: Neuronal dysfunction in patients with closed head injury evaluated by in vivo $1 \mathrm{H}$ magnetic resonance spectroscopy. Invest Radiol 1995, 30:502-506.

44. Signoretti S, Marmarou A, Tavazzi B, Lazzarino G, Beaumont A, Vagnozzi R: N-Acetylaspartate reduction as a measure of injury severity and mitochondrial dysfunction following diffuse traumatic brain injury. J Neurotrauma 2001, 18:977-991.

45. Cecil KM, Lenkinski RE, Meaney DF, Mclntosh TK, Smith DH: High-field proton magnetic resonance spectroscopy of a swine model for axonal injury. J Neurochem 1998, 70:20382044.

46. Rubin $Y$, Cecil K, Wehrli S, Mclntosh TK, Lenkinski RE, Smith DH: High-resolution $1 \mathrm{H}$ NMR spectroscopy following experimental brain trauma. J Neurotrauma 1997, 14:441-449.

47. Alessandri $B$, al-Samsam R, Corwin F, Fatouros $P$, Young HF, Bullock RM: Acute and late changes in N-acetyl-aspartate following diffuse axonal injury in rats: an MRI spectroscopy and microdialysis study. Neurol Res 2000, 22:705-712.

48. Holshouser BA, Tong KA, Ashwal S, Oyoyo U, Ghamsary M, Saunders D, Shutter L: Prospective longitudinal proton magnetic resonance spectroscopic imaging in adult traumatic brain injury. J Magn Reson Imaging 2006, 24:33-40.

49. Signoretti $S$, Marmarou A, Fatouros $P$, Hoyle $R$, Beaumont $A$ Sawauchi S, Bullock R, Young H: Application of chemical shift imaging for measurement of NAA in head injured patients. Acta Neurochir Supp/ 2002, 81:373-375.

50. Adams JH, Graham DI, Murray LS, Scott G: Diffuse axonal injury due to nonmissile head injury in humans: an analysis of $\mathbf{4 5}$ cases. Ann Neurol 1982, 12:557-563.

51. Levin HS: Neuroplasticity following non-penetrating traumatic brain injury. Brain Inj 2003, 17:665-674.

52. Catani M: Diffusion tensor magnetic resonance imaging tractography in cognitive disorders. Curr Opin Neurol 2006, 19: 599-606.

53. Reich DS, Smith SA, Jones CK, Zackowski KM, van Zijl PC, Calabresi PA, Mori S: Quantitative characterization of the corticospinal tract at 3T. AJNR Am J Neuroradiol 2006, 27:2168-2178.

54. Mac Donald CL, Dikranian K, Song SK, Bayly PV, Holtzman DM, Brody DL: Detection of traumatic axonal injury with diffusion tensor imaging in a mouse model of traumatic brain injury. Exp Neurol 2007, 205:116-131.

55. Huisman TA, Schwamm LH, Schaefer PW, Koroshetz WJ, ShettyAlva N, Ozsunar $\mathrm{Y}, \mathrm{Wu} \mathrm{O}$, Sorensen AG: Diffusion tensor imaging as potential biomarker of white matter injury in diffuse axonal injury. AJNR Am J Neuroradiol 2004, 25:370376.

56. Wilde EA, Chu Z, Bigler ED, Hunter JV, Fearing MA, Hanten G, Newsome MR, Scheibel RS, Li X, Levin HS: Diffusion tensor imaging in the corpus callosum in children after moderate to severe traumatic brain injury. J Neurotrauma 2006, 23:14121426.

57. Ewing-Cobbs L, Hasan KM, Prasad MR, Kramer L, Bachevalier J: Corpus callosum diffusion anisotropy correlates with neuropsychological outcomes in twins disconcordant for traumatic brain injury. AJNR Am J Neuroradio/ 2006, 27:879-881.

58. Naganawa $S$, Sato $C$, Ishihra $S$, Kumada $H$, Ishigaki T, Miura $S$ Watanabe M, Maruyama K, Takizawa O: Serial evaluation of diffusion tensor brain fiber tracking in a patient with severe diffuse axonal injury. AJNR Am J Neuroradiol 2004, 25:15531556.

59. Voss HU, Uluc AM, Dyke JP, Watts R, Kobylarz EJ, McCandliss BD, Heier LA, Beattie BJ, Hamacher KA, Vallabhajosula S, et al.: Possible axonal regrowth in late recovery from the minimally conscious state. J Clin Invest 2006, 116:2005-2011.

60. Kimura H, Meaney DF, McGowan JC, Grossman RI, Lenkinski RE, Ross DT, Mclntosh TK, Gennarelli TA, Smith DH: Magnetization transfer imaging of diffuse axonal injury following experimental brain injury in the pig: characterization by magnetization transfer ratio with histopathologic correlation. J Comput Assist Tomogr 1996, 20:540-546.

61. McGowan JC, McCormack TM, Grossman RI, Mendonca R, Chen $\mathrm{XH}$, Berlin JA, Meaney DF, Xu BN, Cecil KM, Mclntosh TK, et al:: Diffuse axonal pathology detected with magnetization transfer imaging following brain injury in the pig. Magn Reson Med 1999, 41:727-733.

62. Bagley LJ, McGowan JC, Grossman RI, Sinson G, Kotapka M, Lexa FJ, Berlin JA, Mclntosh TK: Magnetization transfer imaging of traumatic brain injury. J Magn Reson Imaging 2000, 11:1-8.

63. Fujioka M, Okuchi K, Sakaki T, Hiramatsu K, Miyamoto S, Iwasaki $\mathrm{S}$ : Specific changes in human brain following reperfusion after cardiac arrest. Stroke 1994, 25:2091-2095.

64. Els T, Kassubek J, Kubalek R, Klisch J: Diffusion-weighted MRI during early global cerebral hypoxia: a predictor for clinical outcome? Acta Neurol Scand 2004, 110:361-367.

65. Torbey MT, Bhardwaj A: MR imaging in comatose survivors of cardiac resuscitation. AJNR Am J Neuroradiol 2002, 23:738.

66. Arbelaez A, Castillo M, Mukherji SK: Diffusion-weighted MR imaging of global cerebral anoxia. AJNR Am J Neuroradiol 1999, 20:999-1007.

67. Takahashi S, Higano S, Ishii K, Matsumoto K, Sakamoto K, Iwasaki $Y$, Suzuki M: Hypoxic brain damage: cortical laminar necrosis and delayed changes in white matter at sequential MR imaging. Radiology 1993, 189:449-456.

68. Kim HY, Kim BJ, Moon SY, Kwon JC, Shon YM, Na DG, Lee KH, $\mathrm{Na}$ DL: Serial diffusion-weighted MR Imaging in delayed postanoxic encephalopathy. A case study. J Neuroradiol 2002, 29: 211-215

69. Wijdicks EF, Campeau NG, Miller GM: MR imaging in comatose survivors of cardiac resuscitation. AJNR Am J Neuroradiol 2001, 22:1561-1565.

70. Wartenberg KE, Patsalides A, Yepes MS: Is magnetic resonance spectroscopy superior to conventional diagnostic tools in hypoxic-ischemic encephalopathy? J Neuroimaging 2004, 14:180-186.

71. Kucharczyk J, Moseley M, Kurhanewicz J, Norman D: MRS of ischemic/hypoxic brain disease. Invest Radiol 1989, 24:951. 954.

72. Lo L, Tan AC, Umapathi T, Lim CC: Diffusion-weighted MR imaging in early diagnosis and prognosis of hypoglycemia. AJNR Am J Neuroradiol 2006, 27:1222-1224.

73. Yanagawa Y, Isoi N, Tokumaru AM, Sakamoto T, Okada Y: Diffusion-weighted MRI predicts prognosis in severe hypoglycemic encephalopathy. J Clin Neurosci 2006, 13:696-699.

74. Bottcher J, Kunze A, Kurrat C, Schmidt P, Hagemann G, Witte OW, Kaiser WA: Localized reversible reduction of apparent diffusion coefficient in transient hypoglycemia-induced hemiparesis. Stroke 2005, 36:e20-e22.

75. Cordonnier C, Oppenheim C, Lamy C, Meder JF, Mas JL: Serial diffusion and perfusion-weighted MR in transient hypoglycemia. Neurology 2005, 65:175. 
76. Maruya J, Endoh $\mathrm{H}$, Watanabe $\mathrm{H}$, Motoyama $\mathrm{H}$, Abe $\mathrm{H}$ : Rapid improvement of diffusion-weighted imaging abnormalities after glucose infusion in hypoglycaemic coma. J Neurol Neurosurg Psychiatry 2007, 78:102-103.

77. Thomalla GJ, Kucinski T, Schoder V, Fiehler J, Knab R, Zeumer H, Weiller C, Rother J: Prediction of malignant middle cerebral artery infarction by early perfusion- and diffusion-weighted magnetic resonance imaging. Stroke 2003, 34:1892-1899.

78. Oppenheim C, Samson $Y$, Manai R, Lalam $T$, Vandamme $X$, Crozier S, Srour A, Cornu P, Dormont D, Rancurel G, et al.: Prediction of malignant middle cerebral artery infarction by diffusion-weighted imaging. Stroke 2000, 31:2175-2181.

79. Konishi J, Yamada K, Kizu O, Ito H, Sugimura K, Yoshikawa K, Nakagawa M, Nishimura T: MR tractography for the evaluation of functional recovery from lenticulostriate infarcts. Neurology 2005, 64:108-113.

80. Liang Z, Zeng J, Liu S, Ling X, Xu A, Yu J, Ling L: A prospective study of secondary degeneration following subcortical infarction using diffusion tensor imaging. J Neurol Neurosurg Psychiatry 2007, 78:581-586.

81. Firsching R, Woischneck D, Klein S, Ludwig K, Dohring W: Brain stem lesions after head injury. Neurol Res 2002, 24:145-146.

82. Murdoch I, Nicoll JA, Graham DI, Dewar D: Nucleus basalis of Meynert pathology in the human brain after fatal head injury. $J$ Neurotrauma 2002, 19:279-284.

83. Kinney HC, Samuels MA: Neuropathology of the persistent vegetative state. A review. J Neuropathol Exp Neurol 1994, 53: 548-558.

84. Graham DI, Maxwell WL, Adams JH, Jennett B: Novel aspects of the neuropathology of the vegetative state after blunt head injury. Prog Brain Res 2005, 150:445-455.

85. Adams JH, Connor RC: The shocked head injury. Lancet 1966, $1: 263-264$

86. Adams JH, Doyle D, Ford I, Gennarelli TA, Graham DI, McLellan DR: Diffuse axonal injury in head injury: definition, diagnosis and grading. Histopathology 1989, 15:49-59.

87. Ommaya AK, Gennarelli TA: Cerebral concussion and traumatic unconsciousness. Correlation of experimental and clinical observations of blunt head injuries. Brain 1974, 97:633-654.

88. Laureys S, Giacino JT, Schiff ND, Schabus M, Owen AM: How should functional imaging of patients with disorders of consciousness contribute to their clinical rehabilitation needs? Curr Opin Neurol 2006, 19:520-527.

89. Laureys S, Owen AM, Schiff ND: Brain function in coma, vegetative state, and related disorders. Lancet Neurol 2004, 3:537546.

90. Parvizi J, Damasio A: Consciousness and the brainstem. Cognition 2001, 79:135-160.

91. Plum F, Posner JB: The Diagnosis of Stupor and Coma, 3rd ed. Oxford, UK: Oxford University Press; 1980.

92. Selden NR, Gitelman DR, Salamon-Murayama N, Parrish TB, Mesulam MM: Trajectories of cholinergic pathways within the cerebral hemispheres of the human brain. Brain 1998, 121: 2249-2257.

93. Steriade M: Central core modulation of spontaneous oscillations and sensory transmission in thalamocortical systems. Curr Opin Neurobiol 1993, 3:619-625.

94. Laureys S, Goldman S, Phillips C, Van Bogaert P, Aerts J, Luxen A, Franck G, Maquet P: Impaired effective cortical connectivity in vegetative state: preliminary investigation using PET. Neuroimage 1999, 9:377-382.

95. Firsching R, Woischneck D, Klein S, Ludwig K, Döhring W: Brain stem lesions after head injury. Neurol Res 2002, 24:145-146. 